\title{
A General Procedure for the Conversion of a Carbonyl Group into a Thione Group with Tetraphosphorus Decasulfide
}

J. W. SCHEEREN, P. H. J. OOMS, and R. J. F. NIVARD

Department of Organic Chemistry, Catholic University, Toernooiveld, Nijmegen, The Netherlands

SYNTHESIS 1973, 149-151

GEORG THIEME VERLAG - STUTTGART - ACADEMIC PRESS - NEW YORK - LONDON 


\section{A New Synthesis of 1,2-Benzocyclohepta-1,3-diene \\ G. Dauphin, L. David, P. Duprat, A. Kergomard*, and H. VeSCHAMBRE \\ Université de Clermont - BP 45 - 63170 - Aubière, France}

The recent publication of a new synthesis of homophthalaldehyde ${ }^{1}$ (1) prompts us to report the synthesis of 1,2benzocyclohepta-1,3-diene (3) using a method already described for the cyclization of heptatrienes ${ }^{2}$. o-Allylstyrene (2), obtained from homophthalaldehyde by a Wittig reaction, undergoes cyclization in isopropylamine in the presence of a small amount of suspended sodium to give 1,2-benzocyclohepta-1,3-diene (3) in $55 \%$ yield (based on $o$-allylstyrene). Benzocycloheptene (4) is obtained as a side product in $7 \%$ yield $^{3}$.

The reaction described makes possible the synthesis of 3 from indene in 3 steps, whereas the usual method starting with cinnamaldehyde ${ }^{4}$ requires 4 steps and the method starting with benzosuberone (5) requires two steps.

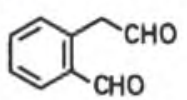

1

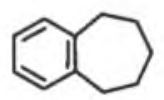

4

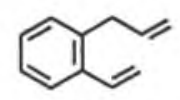

2

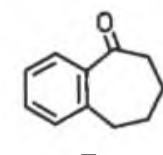

5
o-Allylstyrene (2):

The compound is obtained by reaction of homophthalaldehyde (1) with methyltriphenylphosphonium bromide and sodium amide according to Ref. ${ }^{6}$; yield: $50 \%$; purity (G.L.C.): $>99 \%$.

${ }^{1}$ H-N.M.R. $\left(\mathrm{CDCl}_{3}\right): \delta=3.4(\mathrm{~d}, 2 \mathrm{H}, J=6.0 \mathrm{~Hz}), 4.7-5.1(\mathrm{~m}$, $2 \mathrm{H}), 5.22$ and $5.58(\mathrm{dd}, 2 \mathrm{H}, J=11 \mathrm{~Hz}$ and $J=17 \mathrm{~Hz}), 5.7$ $(\mathrm{m}, 1 \mathrm{H}), 6.95(\mathrm{dd}, 1 \mathrm{H}, J=17 \mathrm{~Hz}$ and $J=11 \mathrm{~Hz}), 7.30(\mathrm{~m}, 4 \mathrm{H}) \mathrm{ppm}$.

1,2-Benzocyclohepta-1,3-diene (3) and Benzocycloheptene (4): A suspension of sodium $(0.08 \mathrm{~g}, 0.003 \mathrm{~g}$-atom) in a solution of $o$-allylstyrene $(2 ; 1.44 \mathrm{~g}, 0.01 \mathrm{~mol})$ in isopropylamine $(10 \mathrm{ml})$ is stirred for $12 \mathrm{hr}$ at room temperature. Sodium is then removed and the solution added to ethanol and then to water. The resultant mixture is extracted with ether, the organic extract evaporated, and the residue subjected to chromatography on silica gel using cyclohexane/ethyl acetate (97/3) as eluent.

Compound 3; yield: $0.8 \mathrm{~g}(55 \%)$; purity (G.L.C.): $>99 \%$

U.V. (cyclohexane): $\lambda_{\max }=253 \mathrm{~nm}(\varepsilon=12000)$.

${ }^{1}$ H-N.M.R. $\left(\mathrm{CDCl}_{3}\right): \delta=1.95(\mathrm{~m}, 2 \mathrm{H}), 2.35(\mathrm{~m}, 2 \mathrm{H}), 2.85(\mathrm{~m}$ 2H), 5.85 (sextet, $1 \mathrm{H}, J=12.5 \mathrm{~Hz}$ and $J=4.5 \mathrm{~Hz}$ ), 6.40 (sextet, $1 \mathrm{H}, J=12.5 \mathrm{~Hz}$ and $J=1.6 \mathrm{~Hz}), 7.05(\mathrm{~s}, 4 \mathrm{H}) \mathrm{ppm}$. The spectrum is identical with that reported in Ref. ${ }^{7}$ (except for the misprint in that publication).

Compound 4; yield: 0.1 g (7\%); purity (G.L.C.): >99\%. The compound was identical with a sample obtained by WolffKishner reduction of 5.

${ }^{1}$ H-N.M.R. $\left(\mathrm{CDCl}_{3}\right): \delta=1.7(\mathrm{~m}, 6 \mathrm{H}), 2.7(\mathrm{~m}, 4 \mathrm{H}), 6.9(\mathrm{~s}, 4 \mathrm{H}) \mathrm{ppm}$.

Received: December 15, 1972

* To whom correspondence should be addressed.
1 P. J. Garratt, K. P. C. Volhart, Synthesis 1971, 423.

2 L. David, A. Kergomard, Ind. Chim. Belges. 32, 744 (1967).

3 L. David, A. Kergomard, Tetrahedron 27, 653 (1971).

4 J. W. Cook, R. Philip, A. R. Somerville, J. Chem. Soc. 1948, 169.

5 R. Huisgen, E. Ranenbusch, G. Seidle, I. Wimmer, Liebigs Ann. Chem. 671, 41 (1964).

6 H. J. Bestmann, O. Kratzer, Chem. Ber. 96, 1899 (1963).

7 E. C. Friedrich, R. L. Holmstead, J. Org. Chem. 37, 2546 (1972).

\section{A General Procedure for the Conversion of a Carhonyl Group into a Thione Group with Tetraphosphorus Decasulfide}

\section{J. W. SCheEREN, P. H.J. OOMS, and R. J.F. NivarD}

Department of Organic Chemistry, Catholic University, Toernooiveld, Nijmegen, The Netherlands

Although tetraphosphorus decasulfide $\left(\mathrm{P}_{4} \mathrm{~S}_{10}\right)$ has been long known ${ }^{1}$ as a reagent for the sulfurization of carbonyl groups, it has never achieved general importance for the synthesis of thiono compounds ${ }^{2,3,4}$. Useful results have only been reported with carboxamides ${ }^{4,5}$ and some cyclic ketones $^{2,3}$. In these synthetic investigations, the carbonyl compound, dissolved in a non-polar solvent such as toluene, was generally refluxed with suspended $\mathrm{P}_{4} \mathrm{~S}_{10}$. The isolation of the sulfur derivative is simple, since residual phosphorus compounds are insoluble in the solvent. Reactions of carbonyl compounds with silicon disulfide or boron sulfide ${ }^{6}$, recently proposed as alternatives for sulfurizations with $\mathrm{P}_{4} \mathrm{~S}_{10}$, have been carried out in the same solvent.

It is remarkable that the use of more polar solvents in these reactions seems to have never been attempted, although a very polar intermediate has been suggested ${ }^{7}$ for the (incompletely understood) sulfurization of amides with $\mathrm{P}_{4} \mathrm{~S}_{10}$, and the catalytic influence of salts on this reaction has long been recognized ${ }^{8}$.

In our investigations on reactions of orthoesters, ketals, and several kinds of carbonyl compounds with $\mathrm{P}_{4} \mathrm{~S}_{10}$, we found that the conversions were much faster in polar solvents than in toluene. Addition of two molar equivalents of sodium sulfide, carbonate, or hydrogen-carbonate to the reaction mixture further accelerated the transformation and clear solutions were obtained with evolution of heat. Under these conditions, several types of carbonyl compounds (1; see Table) could be converted into the corresponding thiono compounds (3), often in higher yields than by known methods.

Little is known about the interaction of $\mathrm{P}_{4} \mathrm{~S}_{10}$ with inorganic salts in organic solvents, but it may be assumed that such solutions contain the anion $\mathrm{X}_{2} \mathrm{PS}_{2}^{\ominus}\left(\mathrm{X}^{\ominus}\right.$ is the monovalent anion in the salt used) in monomeric or polymeric form ${ }^{9,10}$. In solutions prepared from $\mathrm{P}_{4} \mathrm{~S}_{10}$ and sodium carbonate or hydrogen-carbonate, which evolve carbon dioxide, $\mathrm{OPS}_{2}^{\ominus}$ and $\operatorname{SPS}_{2}^{\ominus}$ (2) should thus be present. For sulfurization reactions, such solutions have to be used when freshly prepared, because they become syrupy on standing or heating, probably due to polymerization. 


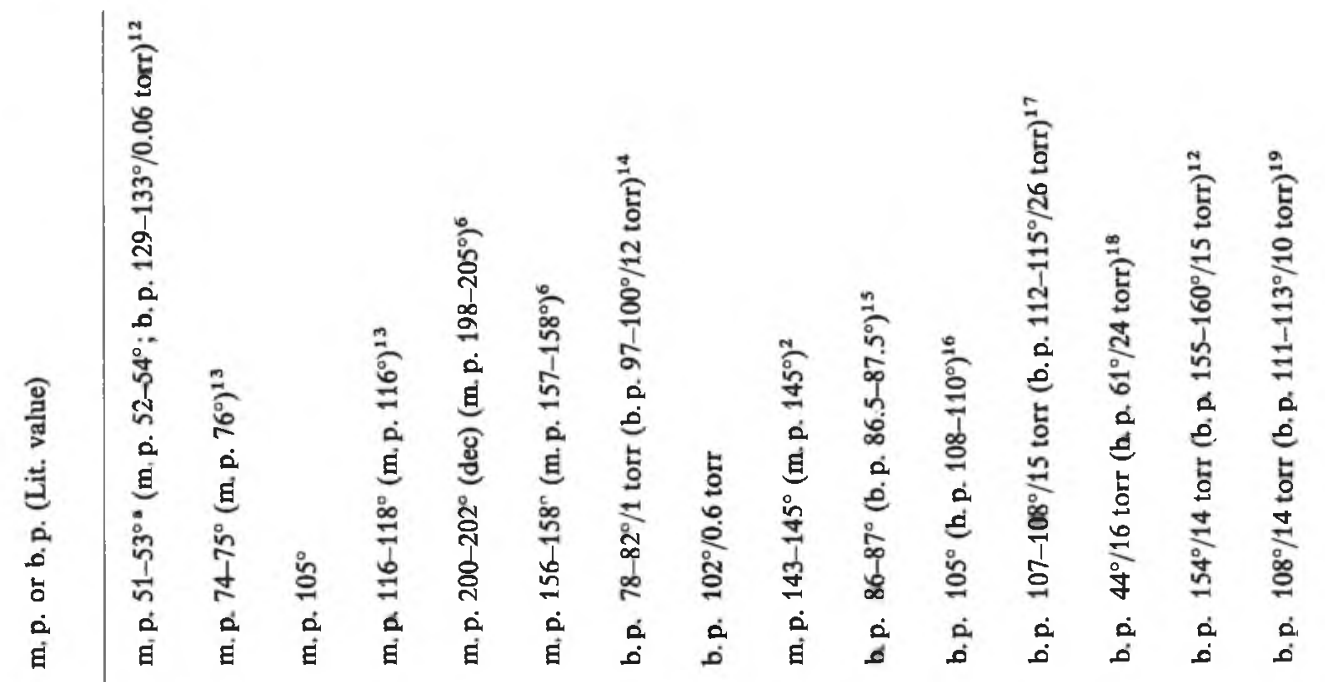

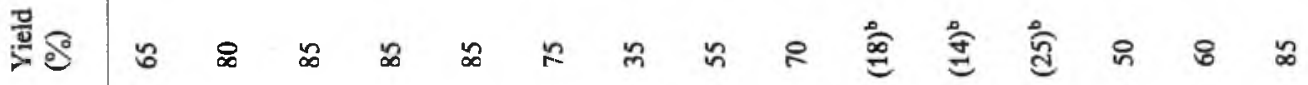

蒫

宛

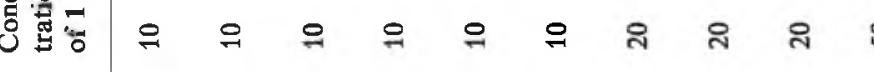

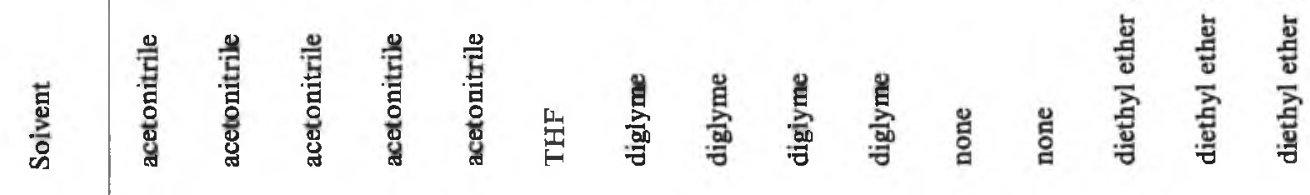
蒙它

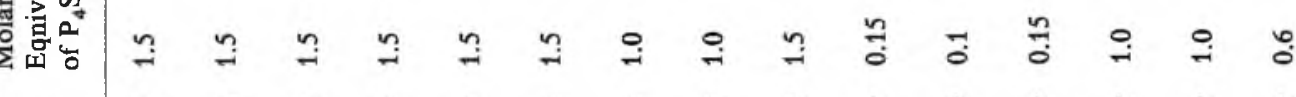

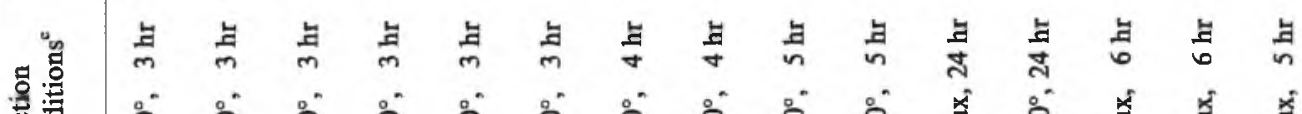



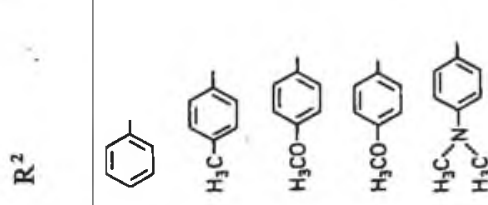<smiles>c1ccc(Cc2ccccc2-c2ccccc2)cc1</smiles>

$\ddot{x}$

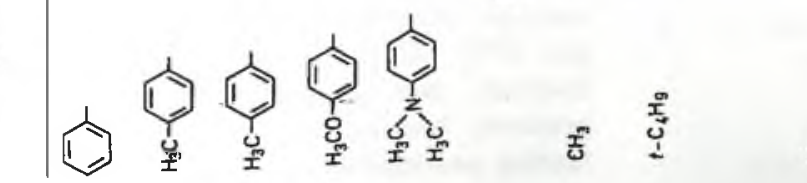

1 b ا 
Sulfurization may be due to nucleophilic attack of these anions on the carbonyl $\mathrm{C}$-atom followed by elimination of $\mathrm{O}_{2} \mathrm{PS}^{\ominus}$ or $\mathrm{OPS}_{2}^{\ominus}$ (4), respectively, e.g.

$$
\begin{aligned}
& \mathrm{R}^{2} \mathrm{R}^{1} \mathrm{C}=0+\mathrm{SPS}_{2}^{\ominus} \longrightarrow\left[\begin{array}{l}
\mathrm{R}^{\mathrm{i}} \backslash \mathrm{S}-\mathrm{PS}_{2} \\
\mathrm{R}^{2} \mathrm{C}
\end{array}\right] \\
& 12 \\
& \longrightarrow \quad \begin{array}{c}
\mathrm{R}^{1} \backslash \mathrm{C}=\mathrm{S} \\
3
\end{array}
\end{aligned}
$$

If $\mathbf{R}^{1}$ or $\mathbf{R}^{2}$ is a good leaving group (as in acid chlorides), no thiono compound (3) is obtained ${ }^{11}$, probably as a consequence of substitution of the leaving group. For aromatic ketones, the reaction rate is lower when $R^{1}$ or $R^{2}$ is electronegative, suggesting that nucleophilic attack of the negative oxygen on phosphorus in the addition product is rate-determining.

In general, the reaction rates are higher in acetonitrile than in the other solvents used (see Table), but the nitrile is not completely inert towards $\mathrm{P}_{4} \mathrm{~S}_{10}$. During work-up under hydrolyzing conditions, thioacetamide is formed as a side product. With more reactive compounds such as carboxamides, even diethyl ether can be used as a solvent, although it does not give clear solutions with the sulfurizing agent. With esters, except formates, the best yields of thione derivatives are obtained when no solvent and only a catalytic amount of sodium sulfide or hydrogen-carbonate is used. We have no explanation for these observations.

\section{Conversion of Carbonyl Compounds into Thiono Compounds; Gen- eral Procedure:}

All sulfurization reactions were performed by dissolving the carbonyl compound in a suitable solvent, adding the solution of $\mathrm{P}_{4} \mathrm{~S}_{10}$ in the same solvent, and adding solid sodium-hydrogen carbonate to the mixture under stirring and at such a rate as allowed by the evolution of carbon dioxide. Stirring was then continued for several hours. Experimental details are given in the Table. Isolation of the products was performed using several, slightly different procedures:

Isolation Procedure A: The reaction mixture was poured into water. The solid product which separated was isolated by filtration, washed several times with water, and dried at low pressure (0.5 torr) and $\sim 50^{\circ}$.

Isolation Procedure B: Ether was added to the reaction mixture. The ethereal solution was washed several times with aqueous sodium-hydrogen carbonate $(5 \%)$ and water, dried, and distilled at low pressure.

Isolation Procedure C: The reaction mixture was diluted with ether, filtered, and the filtrate distilled at low pressure. Isolation Procedure D: Low-boiling reaction products were distilled from residual phosphorus compounds in the reaction mixture at low pressure and collected in a dry-ice trap. They were purified by redistillation.

Using these procedures, the products contained in some cases small amounts (up to $10 \%$ ) of the starting compound. Pure samples $(>95 \%$ ), however, could be obtained by redistillation or recrystallization. O-Ethyl thioacetate contained some S-ethyl thioacetate, which could not be separated by distillation. To obtain a pure sample, the S-ethyl thioacetate was converted into ethyl dithioacetate via the sulfurization described. Separation of O-ethyl thioacetate and ethyl dithioacetate was possible by distillation.

All products were identified and checked for purity by ${ }^{1}$ H-N.M.R. and in the case of aromatic ketones also by I.R. spectrometry. A comparison of the melting and boiling points found with values from the literature is given in the Table.

Received: October 19, 1972

1 A. Kekulé, Liebigs Ann. Chem. 90, 311 (1854).

2 A. Wagner, Thioaldehyde, in: Houben-Weyl, Methoden der Organischen Chemie, 4th Edit., edited by Eu. Müller, Vol. IX, Georg Thieme Verlag, Stuttgart, 1957, p. 699.

${ }^{3}$ S. Patai, The Chemistry of the Carbonyl Group, Interscience, London · New York - Sydney, 1966, Chapter 17.

${ }^{4}$ S. Patai, The Chemistry of Carboxylic Acids and Esters, Interscience, London - New York · Sydney, 1969, Chapter 15.

${ }^{5}$ W. Walter, K.D. Bode, Angew. Chem. 78, 517 (1966); Angew. Chem. Internat. Edit. 5, 447 (1966).

${ }^{6}$ F.M. Dean, J. Goodchild, A.W. Hill, J. Chem. Soc. [C] 1969, 2192.

7 A.L. Long, A. Tulley, J. Chem. Soc. 1964, 1190.

${ }^{8}$ K. Kindler, Liebigs Ann. Chem. 431, 187 (1923).

9 Mellor's Comprehensive Treatise on Inorganic and Theoretical Chemistry, Vol. VIII, Supp. III, Longmans, London, 1970, p. 427.

10 E. Thilo, G. Ladwig, Monatsber. Deutsch. Akad. Wiss. Berlin 4, 720 (1962).

11 see also: S. Scheithauer, R. Mayer, Chem. Ber. 98,829 (1965).

12 H. Viola, S. Scheithauer, R. Mayer, Chem. Ber. 101, 3517 (1968).

${ }_{13}^{13}$ N. Lozach, G. Guillouzo, Bull. Soc. Chim. France 1957, 1221.

14 R. Mayer, H. Berthold, Chem. Ber. 96, 3096 (1963).

15 U. Schmidt, E. Heymann, K. Kabitzke, Chem. Ber. 96, 1478 (1963).

16 P. Reynand, R.C. Moreau, Bull. Soc. Chim. France 1964, 2999.

17 M. Delepine, Bull. Soc. Chim. France [4] 9, 904 (1911).

18 N.H. Leon, R. S. Asquith, Tetrahedron 26, 1719 (1970).

19 H. Eilingsfeld, M. Seefelder, H. Weidinger, Chem. Ber. 96, 2671 (1963).

\section{Mixed Acylals; Synthesis of Alkylidene Carboxylate Formates}

\section{J.W. SCHEEREN and W. J. M. TAX}

Department of Organic Chemistry, Catholic University, Toernooiveld, Nijmegen, The Netherlands

and R. SCHIJF*

Laboratory of Organic Chemistry, University of Leiden, The Netherlands

Since excellent synthetic procedures for the preparation ${ }^{1,2}$ of pure mixed anhydrides of formic acid and other carboxylic acids are now available, it appeared worthwhile to investigate the reactivity of these anhydrides towards aldehydes, which might lead to a synthesis of the hitherto unknown mixed alkylidene dicarboxylates of formic acid and other carboxylic acids. 
The relevant mixed anhydrides decompose readily at higher temperatures and in the presence of acids and bases. Thus, we performed our first experiments at $0^{\circ}$ using iron(III) chloride $^{3}$ as a catalyst; formaldehyde was introduced into ethereal solutions of mixed anhydrides. However, the yields of mixed acylals obtained under these conditions were very low due to polymerization of the aldehyde and decomposition (evolution of gas) of the anhydride.

With acetaldehyde, the yields were better (up to $50 \%$ ), but the reaction mixtures always contained substantial amounts of the ethylidene dicarboxylate with identical acid residues. In some cases, complete separation of this side product from the desired alkylidene carboxylate formate was difficult or even impossible. Ethylene diformate was never found, probably due to its low stability.

Because the use of pure mixed anhydrides did not prevent the formation of acylals with identical acid residues, we modified the procedure, replacing the mixed anhydride by a formic acid-carboxylic acid mixture. It is known that such mixtures contain the mixed anhydride as a consequence of equilibrium (1).
(1)<smiles>[R]C=[N+]=[Ca]</smiles>

(2)<smiles>[R]C(=O)OC([R])OC([R])=O</smiles><smiles>[R]C(=O)OC([R])OC([R])=O</smiles>

In Reaction (2), the weaker acid will react more readily than formic acid, though not exclusively. Any alkylidene diformate resulting from the participation of formic acid in Reaction (2) will in any case decompose in the acidic medium; it was never found as side product. The hypothetical intermediate semi-acylal 3 could not be detected

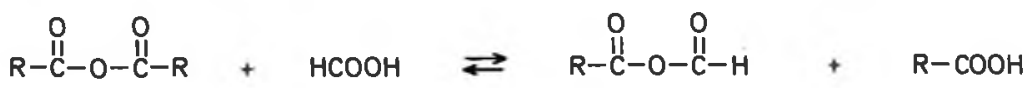

The best results were obtained when the anhydride and formic acid were used in excess $(50 \%$ and $500 \%$, respectively). If the molar ratio between aldehyde and anhydride is higher, $\alpha, \alpha^{\prime}$-acyloxyethers, e.g.<smiles>[R]C(=O)OC([R])OC=O</smiles>

are found as side products 5 .

Among the several possible catalysts tested $\left(\mathrm{FeCl}_{3}, \mathrm{H}_{2} \mathrm{SO}_{4}\right.$, $\mathrm{P}_{2} \mathrm{O}_{5}, \mathrm{HCOONa}$, pyridine), phosphorus pentoxide appeared to be the most effective.

The alkylidene carboxylate formates (5) prepared by this procedure are listed in the Table. The compounds were identified and tested for purity by N.M.R. In all compounds, the $\mathrm{H}_{\alpha}$-peak of<smiles>[R]COC(=O)OC([R])=O</smiles>

was found between $\delta=6.5$ and $6.9 \mathrm{ppm}$ (TMS as internal references).

In view of the strong acylating and preferential formylating ability of the formic acid - acetic anhydride system ${ }^{6}$ a tentative reaction scheme might be represented as follows. (by ${ }^{1}$ H-N.M.R. analysis) in the reaction mixture because the equilibrium lies far on the left side, and because compound 3 is used in Reaction (3).

A similar scheme, combining Reactions (2), (4), and (5) but not involving Reaction (3), could explain the formation of $\alpha, \alpha^{\prime}$-diacyloxy ethers (7) when the aldehyde is used in excess.<smiles>[R]C=C[C@H](C)OC([R])OC([R])(O)OC([R])=O</smiles><smiles>[R]C(=O)OC=CC([R])C([R])(O)OC([R])C(=O)O</smiles><smiles>[R]C(=O)OC([R])OC([R])C([R])OC([3H])=O</smiles>

Preparation of Mixed Acylals; General Procedure:

The carboxylic anhydride is mixed with formic acid in a molar ratio of 1:5. After standing for $30 \mathrm{~min}$ at room temperature, an aldehyde ( $2 / 3$ equivalents based on anhydride) and phosphorus pentoxide $(0.5 \mathrm{~g}$ per mol of aldehyde) are added. The mixture becomes warm and a gas is evolved. After the mixture has been left for $3 \mathrm{hr}$ at room temperature, formic acid is evaporated at reduced pressure (15 torr), ether is added, and the ethereal solution is extracted several times with aqueous sodium-hydrogen carbonate and finally with water. The solution is dried with sodium sulfate, ether is evaporated, and the residue is distilled using a Vigreux column $(80 \times 1.2 \mathrm{~cm})$. Alkylidene acetate formates free from alkylidene diacetates can only be obtained by distillation of the crude products using a spinning-band column of at least 25 theoretical plates. 